\title{
Unveiling the Role of Hydroxyl Architecture on Polysulfide Trapping for High-Performance Lithium-Sulfur Batteries
}

Xiaoyan $\operatorname{Ren}^{\dagger}$, Qi Sun ${ }^{\dagger} \star$, Youliang Zhu ${ }^{\S}$, Wenbo Sun ${ }^{\dagger}$, Yang $\mathrm{Li}^{*}{ }^{*}$, and Lehui $\mathrm{Lu}^{*, \dagger,}$

†State Key Laboratory of Electroanalytical Chemistry, Changchun Institute of Applied Chemistry, Chinese Academy of Sciences, Changchun 130022, Jilin, People's Republic of China

University of Science and Technology of China, Hefei 230026, Anhui, People’s Republic of China

${ }^{\S}$ State Key Laboratory of Polymer Physics and Chemistry, Changchun Institute of Applied Chemistry, Chinese Academy of Sciences, Changchun 130022, Jilin, People's Republic of China

*Corresponding authors: liyang1007@ ciac.ac.cn (Dr. Yang Li) lehuilu@ciac.ac.cn (Prof. Dr. Lehui Lu) 
Table S1. Binding energy calculation about the relationships between CDs and $\mathrm{Li}_{2} \mathrm{~S}_{\mathrm{x}}$ species.

\begin{tabular}{ccccc}
\hline $\begin{array}{c}\text { Host/guest/ } \\
\text { Binding Energy }(\mathbf{e V})\end{array}$ & $\boldsymbol{\alpha}-\mathrm{CD}$ & $\boldsymbol{\beta}-\mathrm{CD}$ & $\boldsymbol{\gamma}$-CD & $\begin{array}{c}\text { Undoped } \\
\text { carbon }\end{array}$ \\
\hline $\mathbf{L i}_{2} \mathbf{S}_{\mathbf{2}}$ & -3.41 & -3.47 & -2.06 & -1.90 \\
$\mathbf{L i}_{2} \mathbf{S}_{\mathbf{4}}$ & -1.89 & -3.22 & -1.93 & -1.90 \\
$\mathbf{L i}_{2} \mathbf{S}_{6}$ & -2.06 & -3.00 & -1.91 & -1.90 \\
$\mathbf{L i}_{2} \mathbf{S}_{8}$ & -2.36 & -2.91 & -1.87 & -1.85 \\
\hline
\end{tabular}

Table S2. Bond length between $\mathrm{CD}$ and $\mathrm{Li}_{2} \mathrm{~S}_{\mathrm{x}}$ species.

\begin{tabular}{cccc}
\hline $\begin{array}{c}\text { Host/guest/ } \\
\text { Bond length }(\AA)\end{array}$ & $\boldsymbol{\alpha}$-CD & $\boldsymbol{\beta}-\mathbf{C D}$ & $\boldsymbol{\gamma}$-CD \\
\hline $\mathbf{L i}_{2} \mathbf{S}_{\mathbf{2}}$ & $1.960,1.969$ & $1.912,1.942,1.929$ & $1.886,1.915$ \\
$\mathbf{L i}_{2} \mathbf{S}_{\mathbf{4}}$ & $1.989,1.992$ & $1.888,1.928,1.929$ & $1.886,1.923$ \\
$\mathbf{L i 2} \mathbf{S}_{\mathbf{6}}$ & $1.966,1.978$ & $1.903,1.922,1.932$ & $1.882,1.909$ \\
$\mathbf{L i 2} \mathbf{S}_{\mathbf{6}}$ & $1.974,1.942$ & $1.904,1.929,1.934$ & $1.872,1.899$ \\
\hline
\end{tabular}
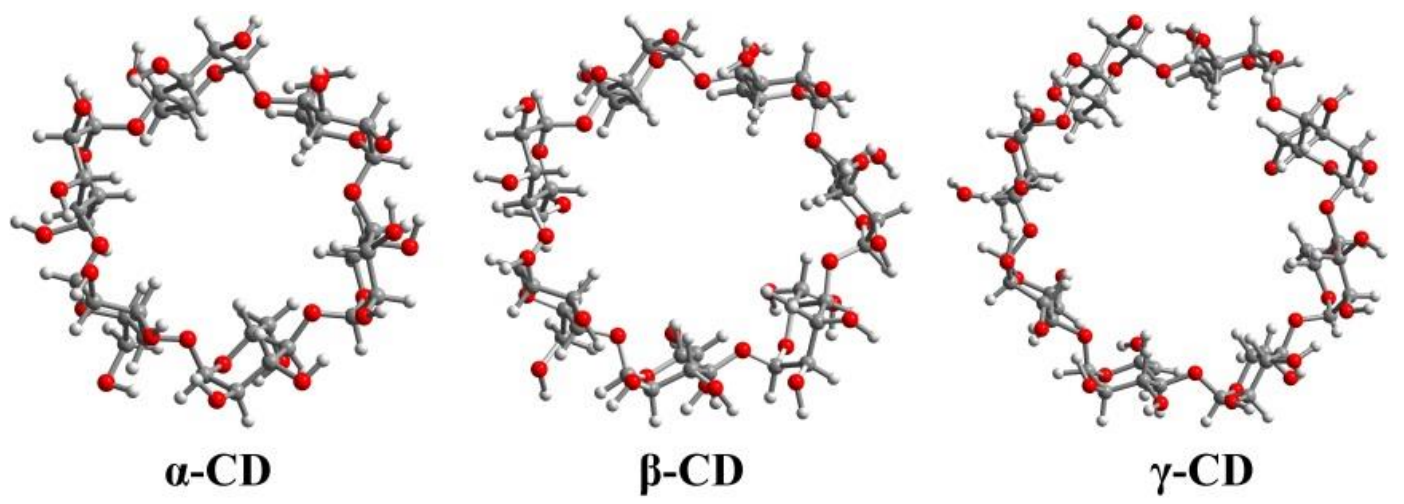

Figure S1. The structures of three natural CDs, named $\alpha-C D, \beta-C D, \gamma-C D$, respectively. 


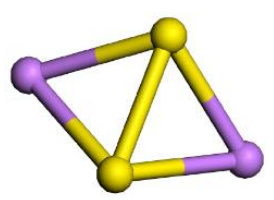

$\mathbf{L i}_{2} \mathbf{S}_{2}$

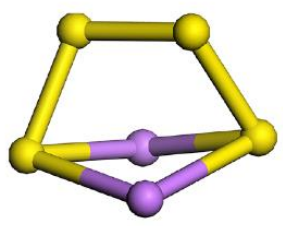

$\mathrm{Li}_{2} \mathrm{~S}_{4}$

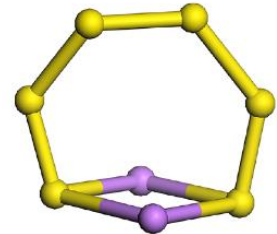

$\mathrm{Li}_{2} \mathrm{~S}_{6}$

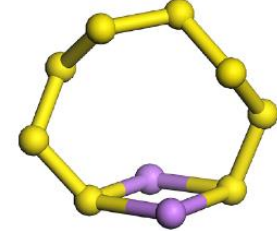

$\mathrm{Li}_{2} \mathrm{~S}_{8}$

Figure S2. Stable configurations for $\operatorname{Li}_{2} S_{x}(x=2-8)$ clusters, agreeing well with the previous work.

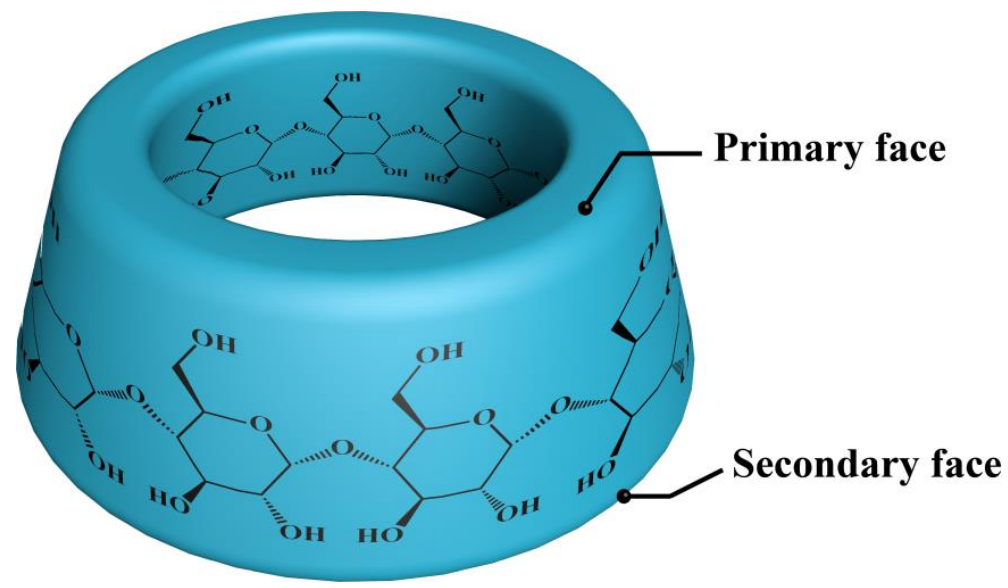

Figure S3. Schematic representation of 3-D structure of cyclodextrins. The primary face is made of primary $\mathrm{OH}$ groups located on the narrow torus. And the secondary face is made of secondary $\mathrm{OH}$ groups on the wide torus. 

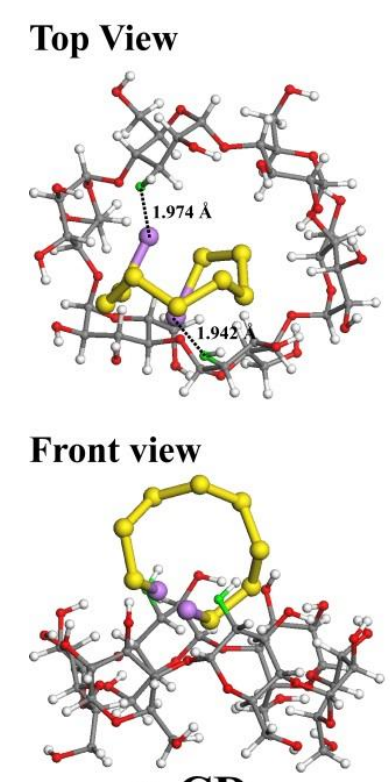
$\alpha-C D$
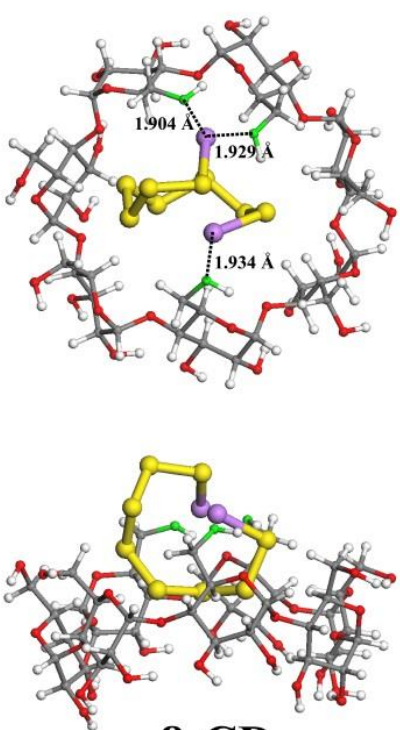

B-CD
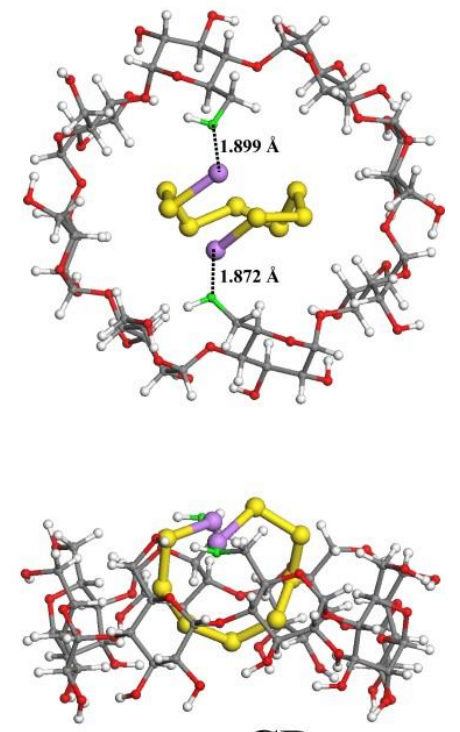

$\gamma-\mathbf{C D}$

Figure S4. Two views (top and front) of the binding connectivity between various CD molecules and $\mathrm{Li}_{2} \mathrm{~S}_{8}$. The $\mathrm{C}, \mathrm{H}, \mathrm{O}$ (the binding oxygen), $\mathrm{Li}$, and $\mathrm{S}$ atoms are represented by the colors gray, light gray, red (green), purple, and yellow, respectively.

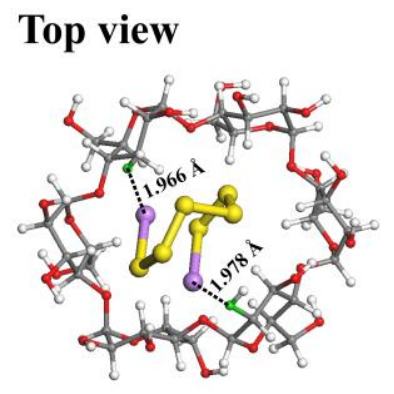

Front view

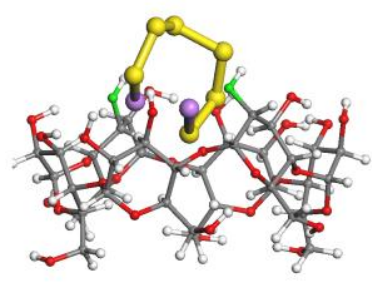

$\alpha-C D$
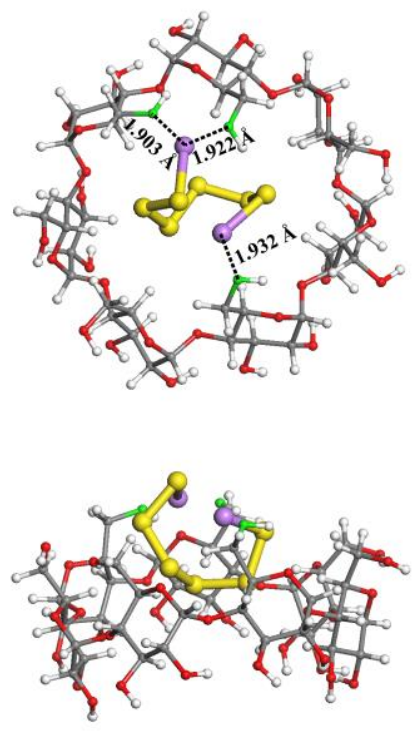

$\boldsymbol{\beta}-\mathbf{C D}$
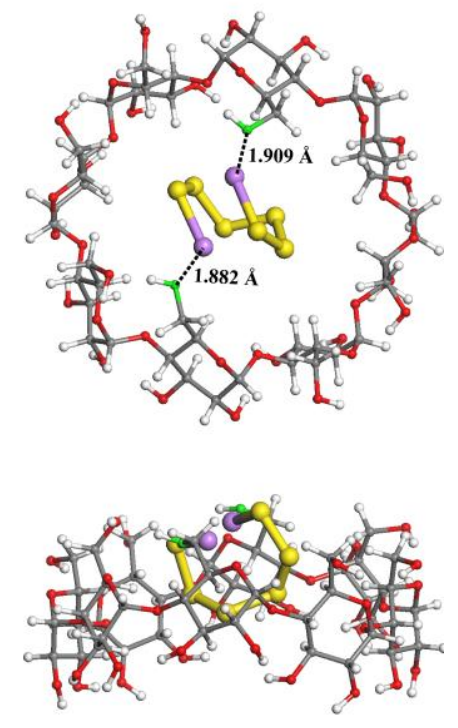

$\gamma-\mathbf{C D}$

Figure S5. Two views (top and front) of the binding connectivity between various CD molecules and $\mathrm{Li}_{2} \mathrm{~S}_{6}$. The $\mathrm{C}, \mathrm{H}, \mathrm{O}$ (the binding oxygen), $\mathrm{Li}$, and $\mathrm{S}$ atoms are represented by the colors gray, light gray, red (green), purple, and yellow, respectively. 


\section{Top view}
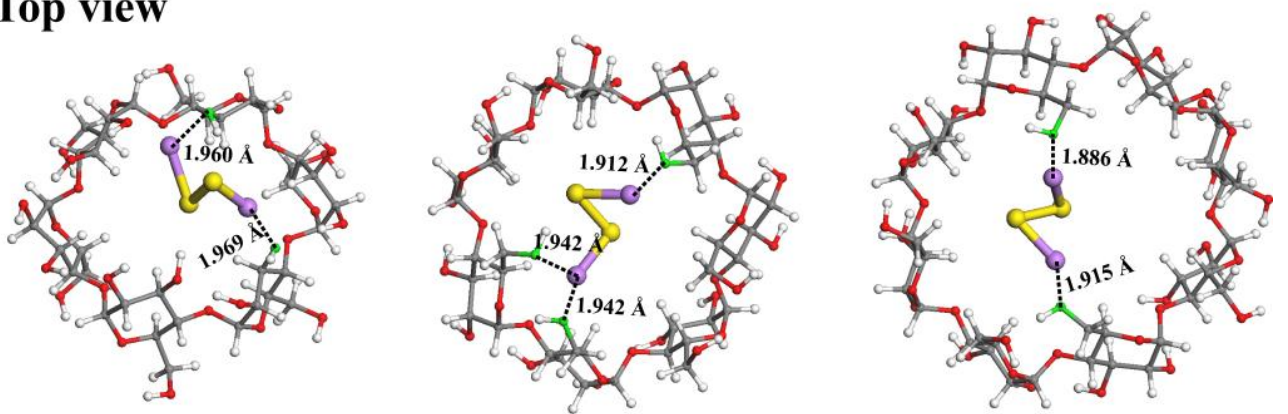

\section{Front view}

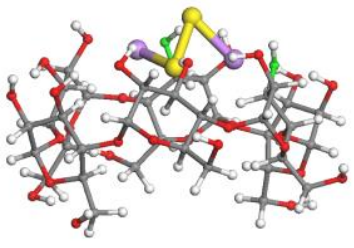

$\alpha-C D$

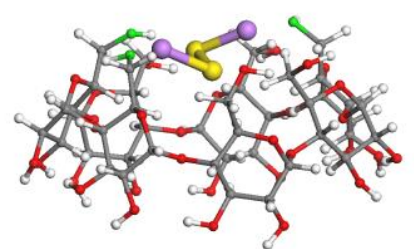

B-CD

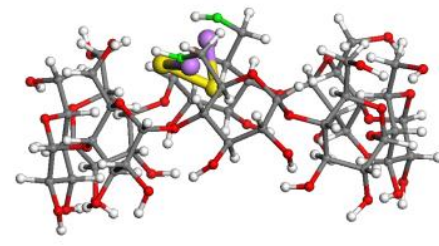

$\gamma-\mathrm{CD}$

Figure S6. Two views (top and front) of the binding connectivity between various CD molecules and $\mathrm{Li}_{2} \mathrm{~S}_{2}$. The $\mathrm{C}, \mathrm{H}, \mathrm{O}$ (the binding oxygen), $\mathrm{Li}$, and $\mathrm{S}$ atoms are represented by the colors gray, light gray, red (green), purple, and yellow, respectively.
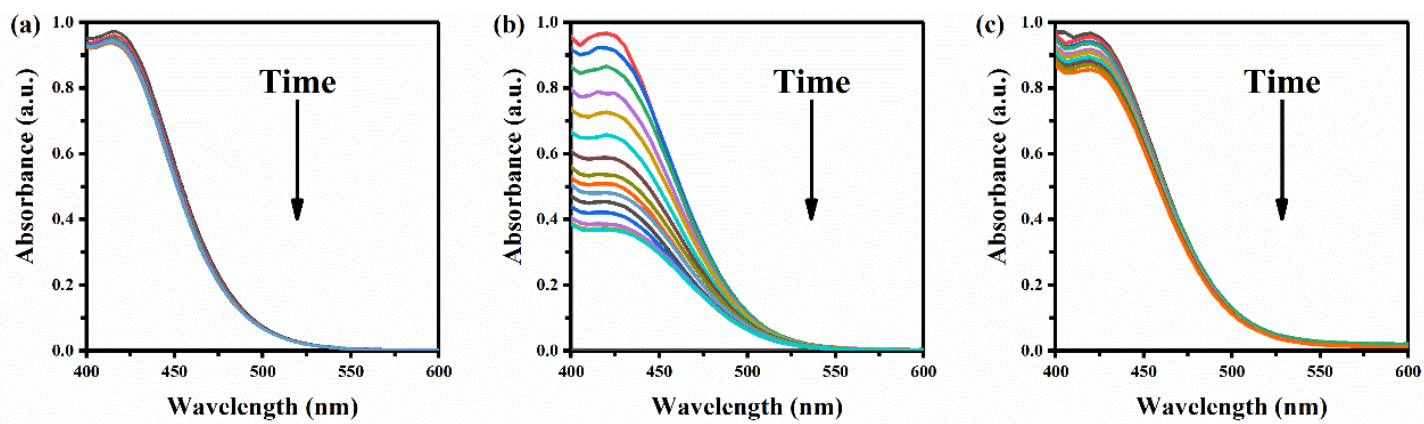

Figure S7. The change of UV-vis adsorption with (a) $\alpha-C D$, (b) $\beta-C D$, and (c) $\gamma-C D$ fixed into polyacrylonitrile nanofibers by electrostatic spinning. 


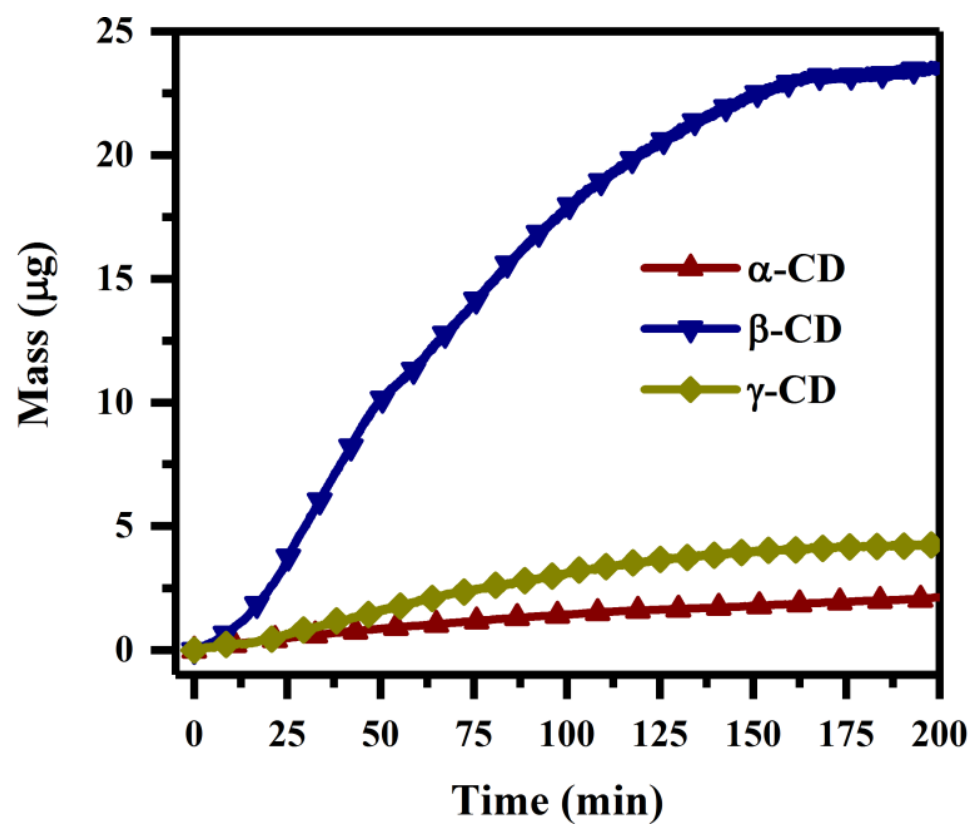

Figure S8. The mass changes using various $\mathrm{CD}$ molecules as pre-coating layers.
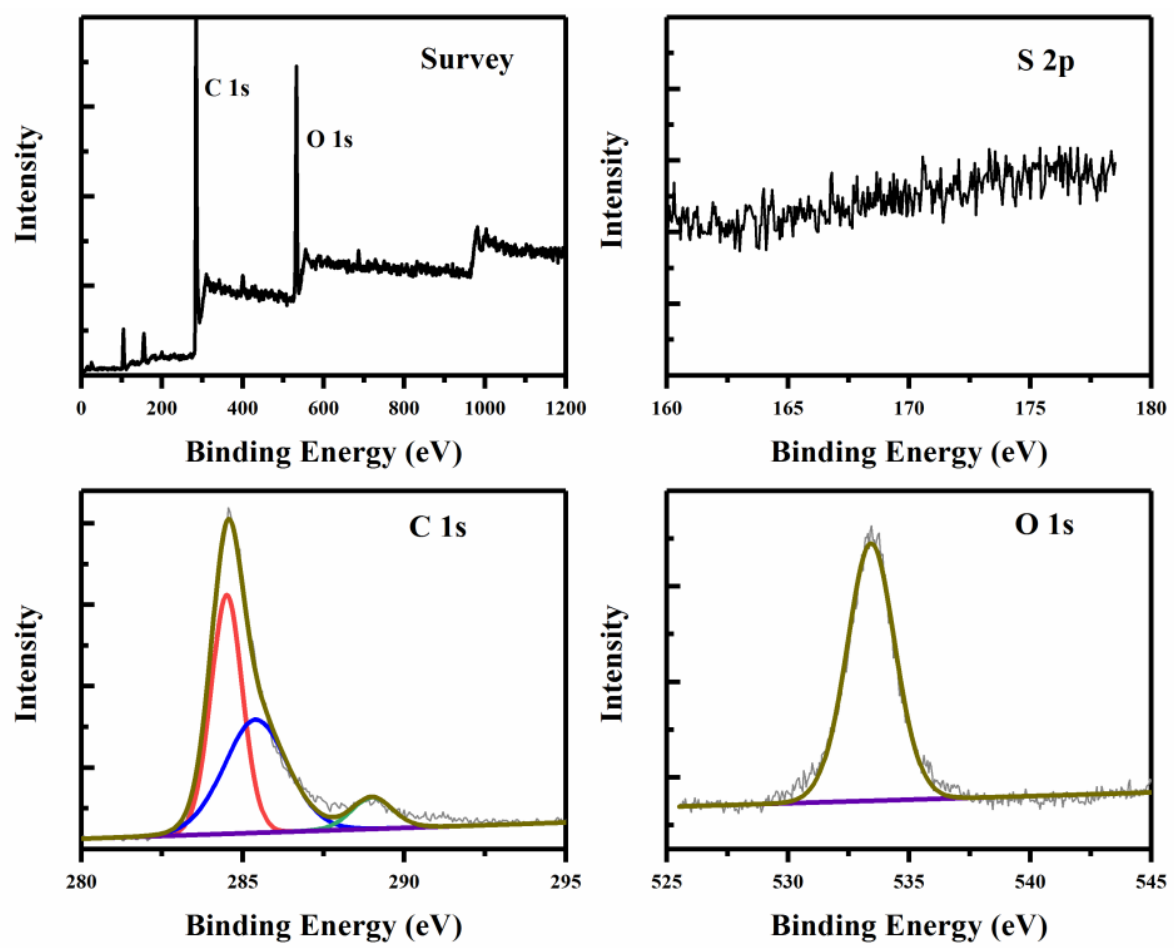

Figure S9. XPS spectrum of commercial CMK-3. 

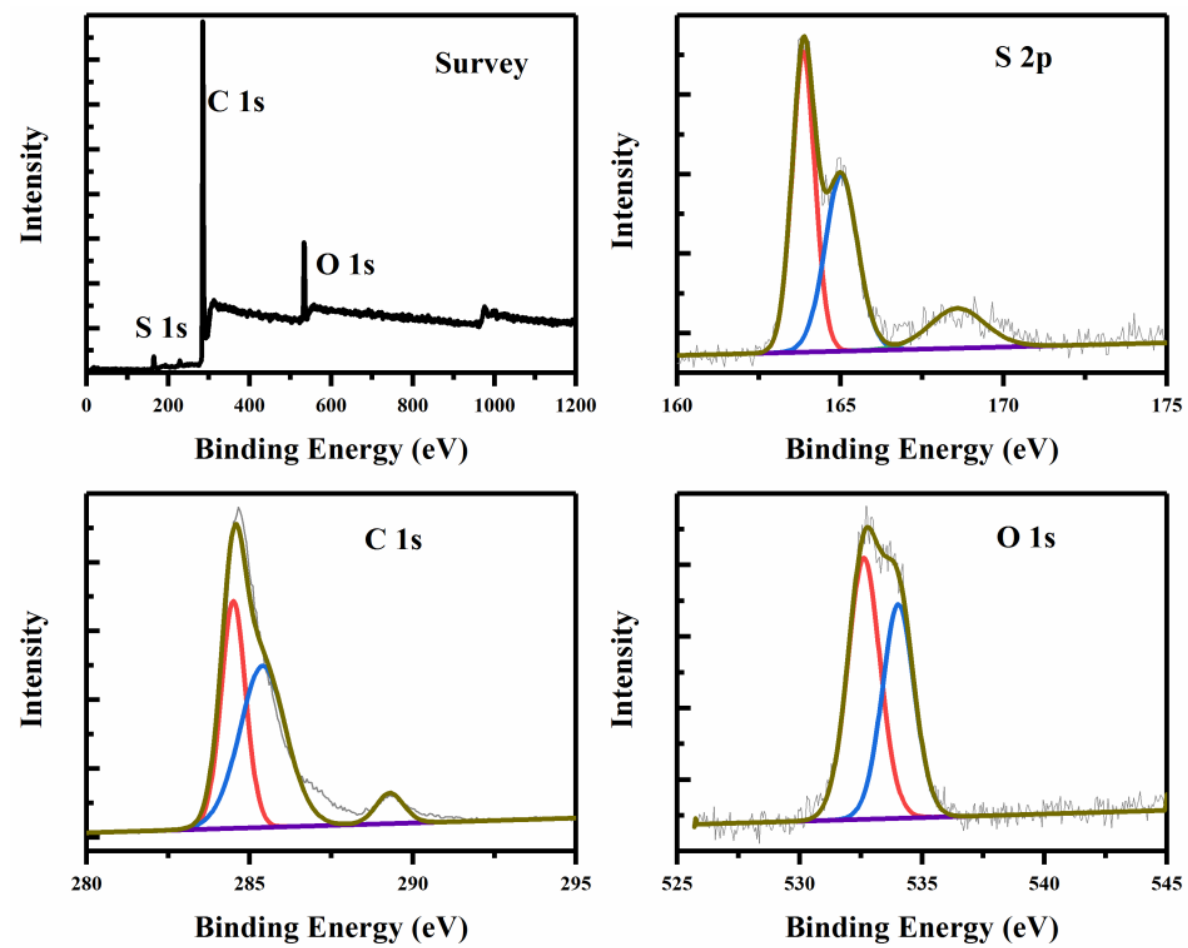

Figure S10. XPS spectrum of $\beta-\mathrm{CD} @ \mathrm{CMK}-3 @ \mathrm{~S}$.

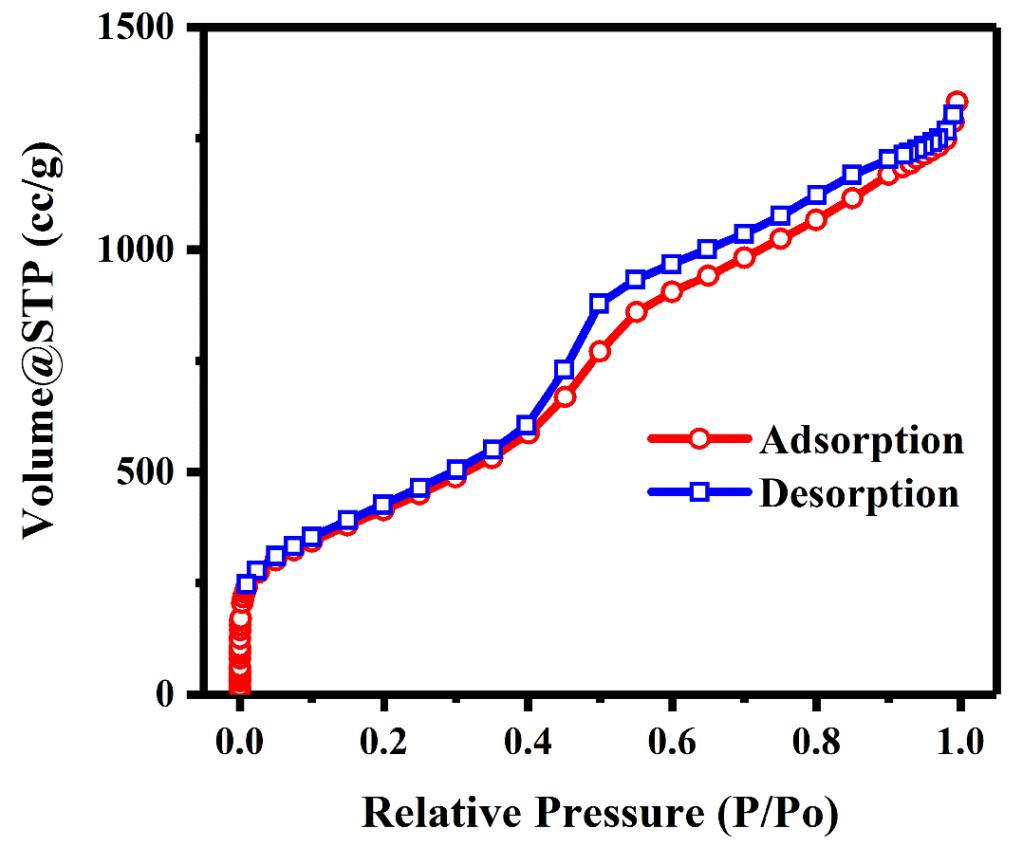

Figure S11. $\mathrm{N}_{2}$ adsorption isotherm of commercial CMK-3 material. 


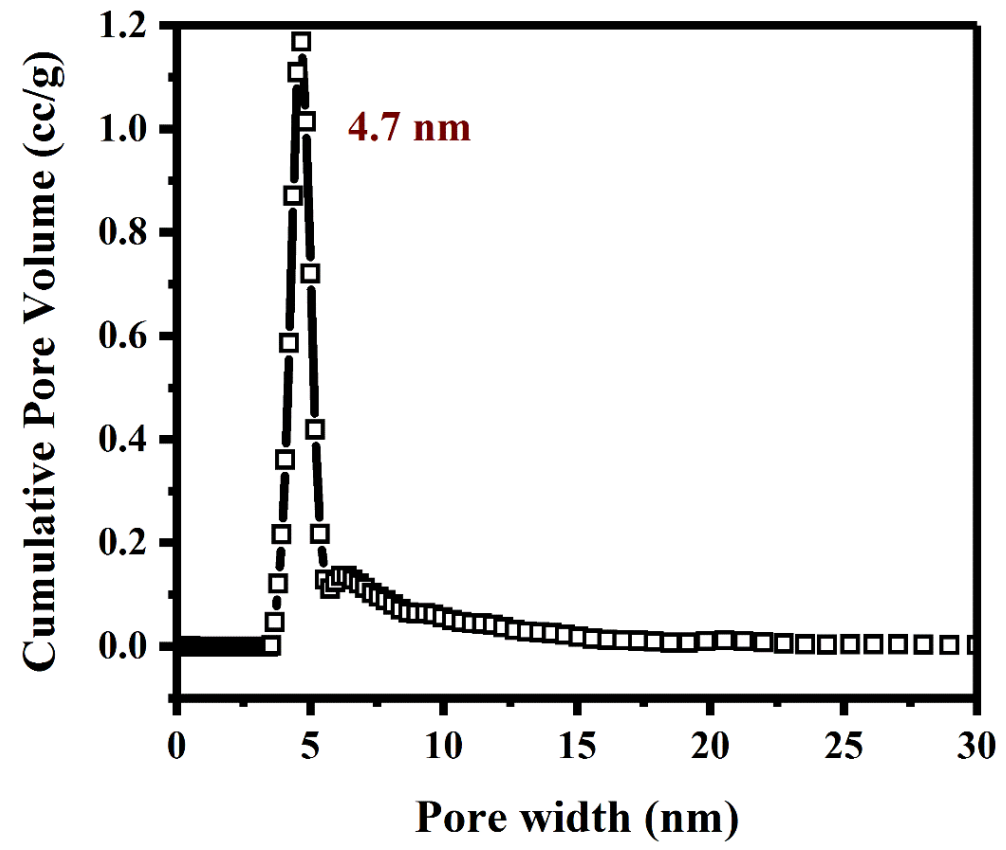

Figure S12. The distribution of pore diameter of commercial CMK-3 material.

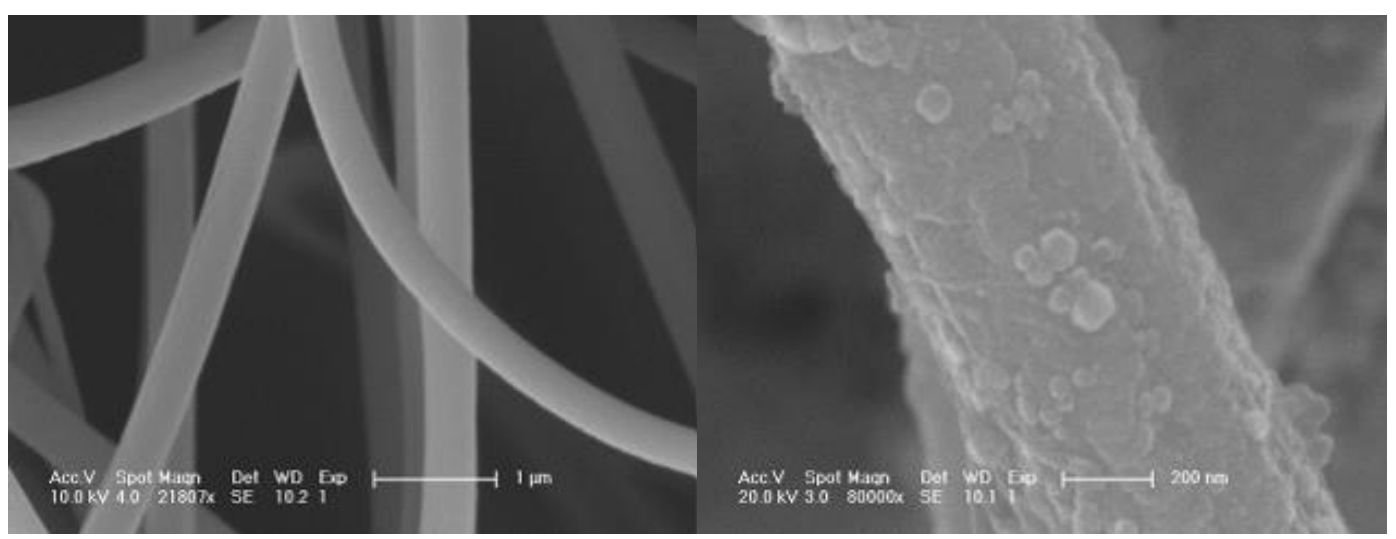

Figure S13. SEM images of $\beta$-CD-fixed nanofibers with different scale bar. 


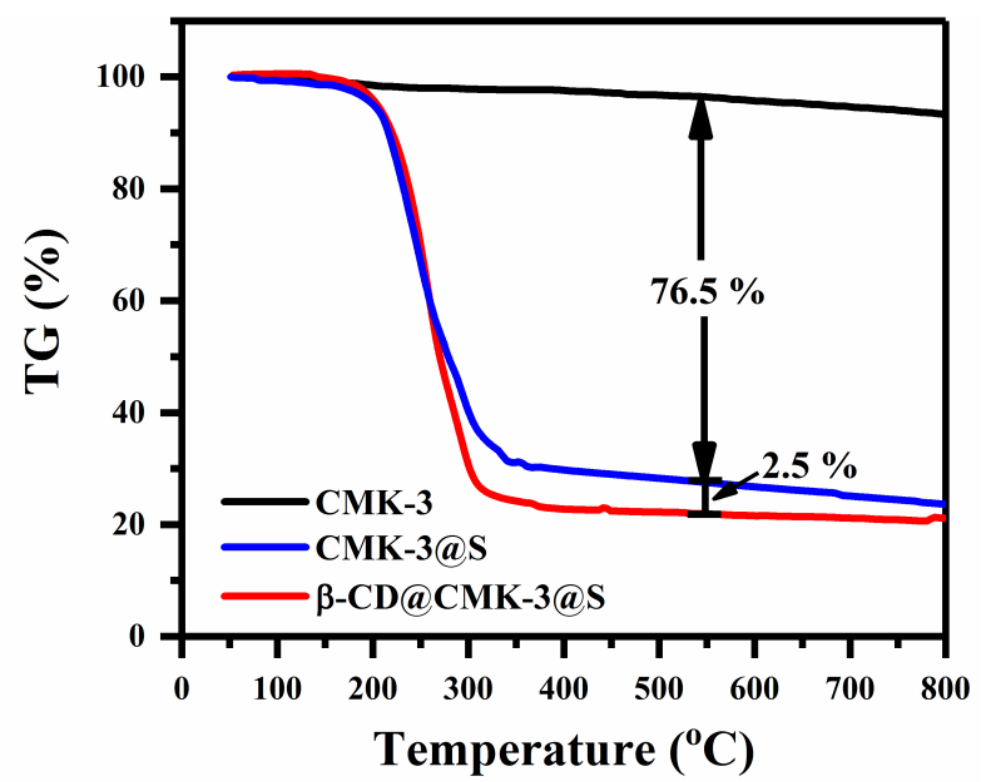

Figure S14. TGA analysis of CMK-3, CMK-3@S, and $\beta-C D @ C M K-3 @ S$.

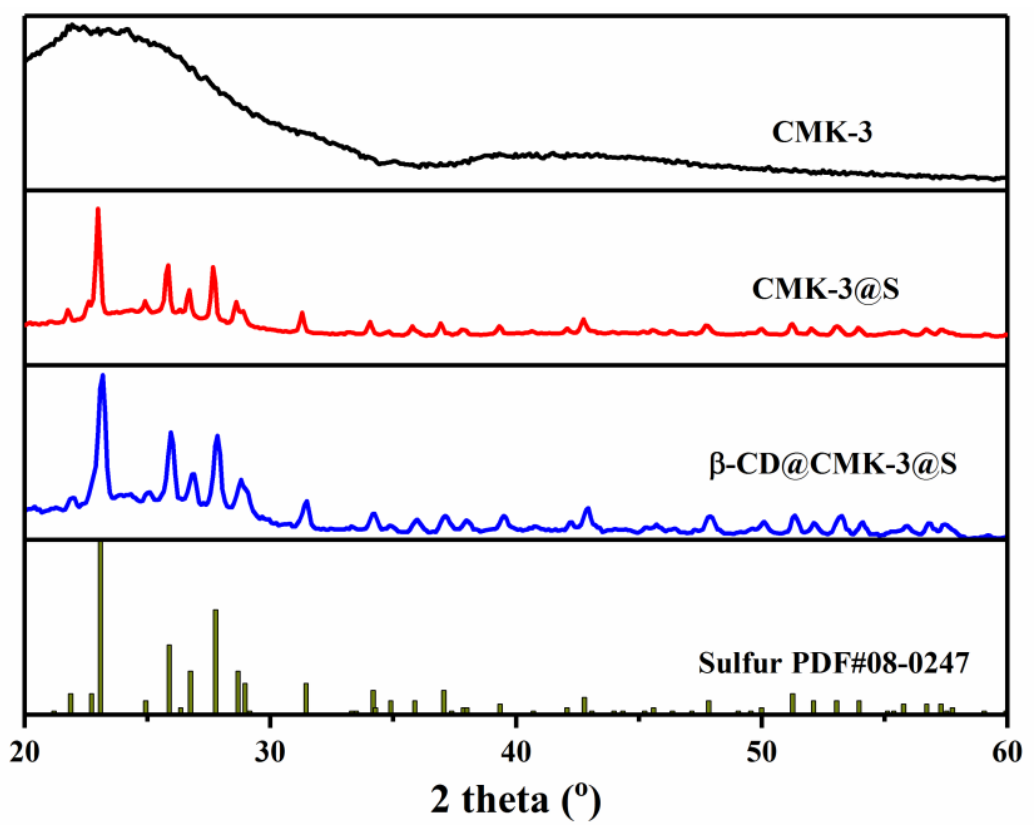

Figure S15. XRD patterns of CMK-3, CMK-3@S, $\beta-C D @ C M K-3 @ S$ and sulfur powder. The XRD patterns before and after $\beta$-CD coating exhibited similar peaks, as the ultrathin layer of $\beta-\mathrm{CD}$ was difficult to detect. 


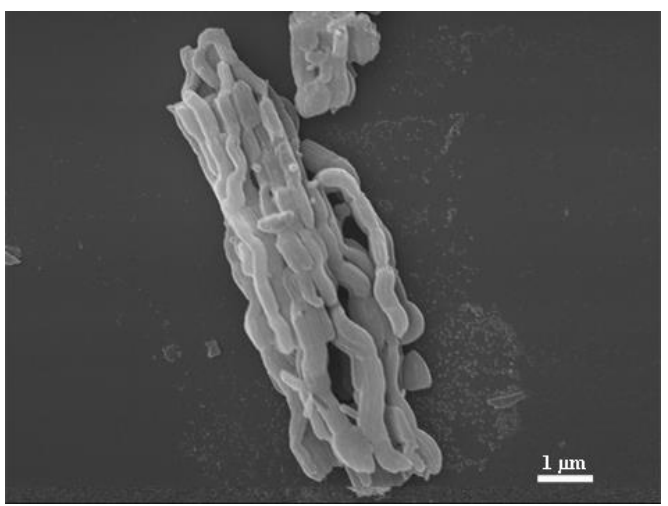

Figure S16. SEM image of commercial CMK-3 material.
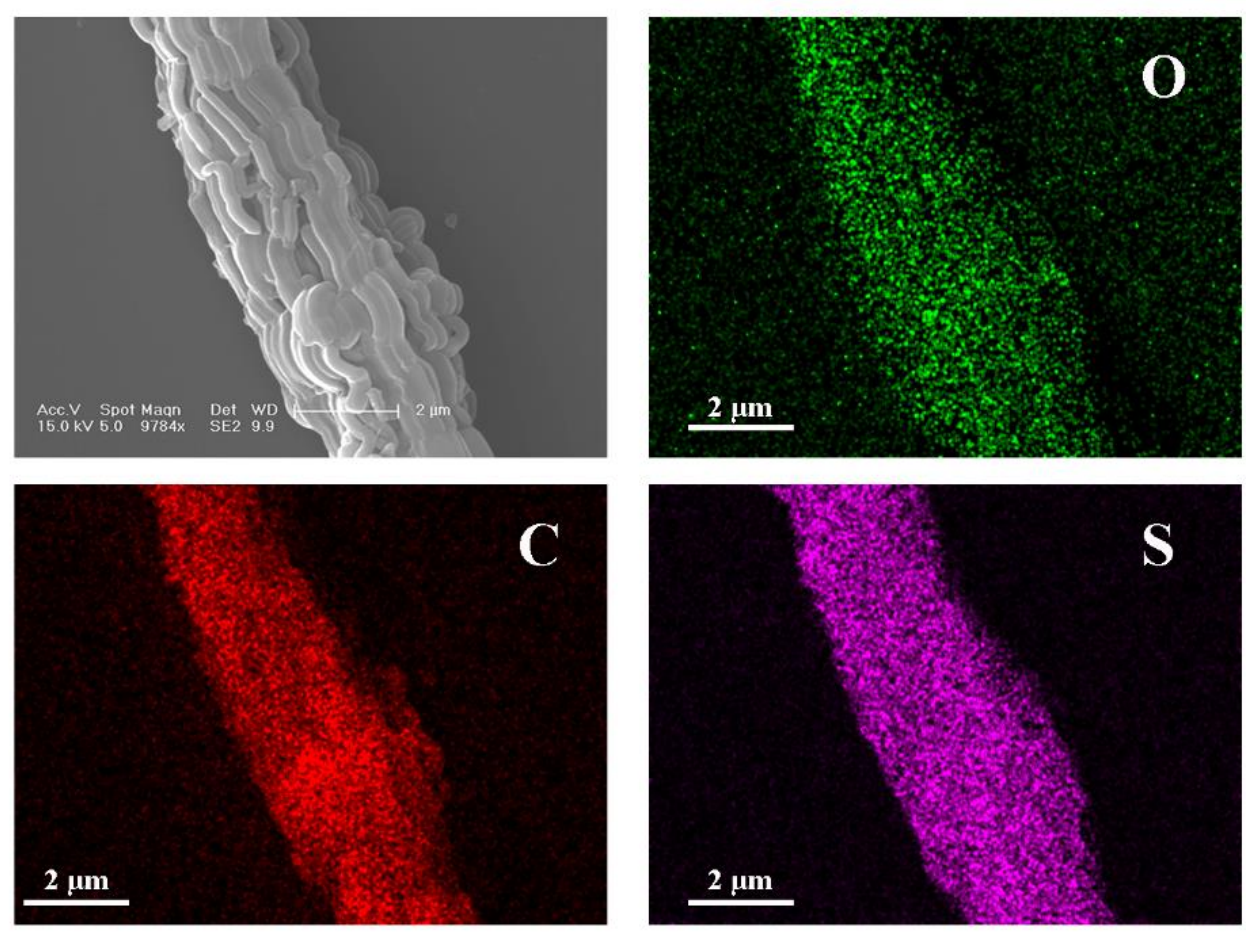

Figure S17. SEM image and element mapping of $\beta-C D @ C M K-3 @ S$. 


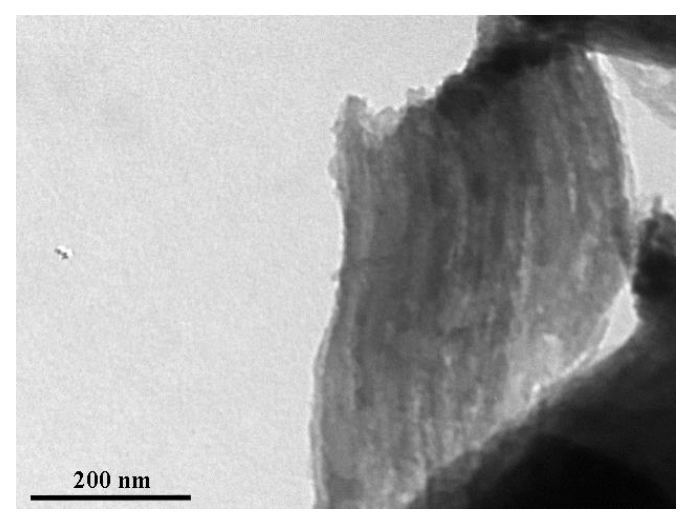

Figure S18. TEM image of $\beta-C D @ C M K-3 @ S$ material.

Table S3. The changes of element composition in the as-prepared materials.

\begin{tabular}{|c|c|c|c|c|}
\hline Name & $\mathrm{C}(\mathrm{wt} \%)$ & $O(w t \%)$ & H (wt \%) & S (wt \%) \\
\hline CMK-3 & 88.18 & 9.74 & 1.68 & 0.40 \\
\hline CMK-3@S & 18.71 & 1.83 & 1.52 & 78.0 \\
\hline a-CD@CMK-3@S & 16.71 & 7.26 & 1.98 & 73.99 \\
\hline$\beta-C D @ C M K-3 @ S$ & 16.62 & 11.41 & 1.66 & 70.30 \\
\hline r-CD@CMK-3@S & 13.94 & 13.46 & 1.80 & 70.8 \\
\hline
\end{tabular}

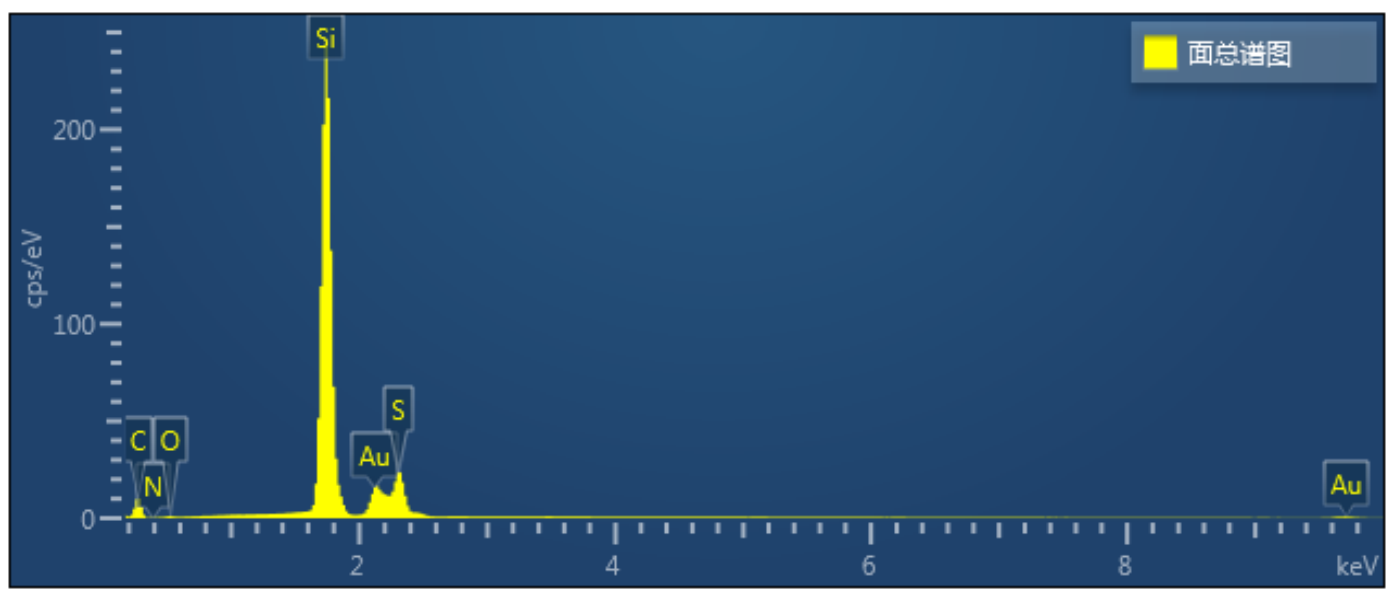

Figure S19. EDX result of $\beta-C D @ C M K-3 @ S$. 
(a)
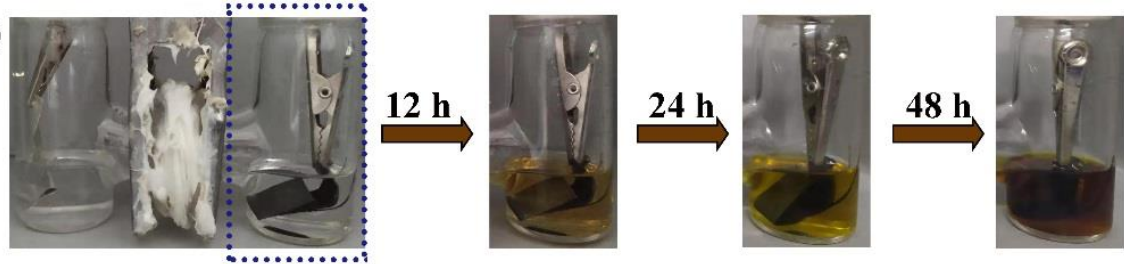

(b)
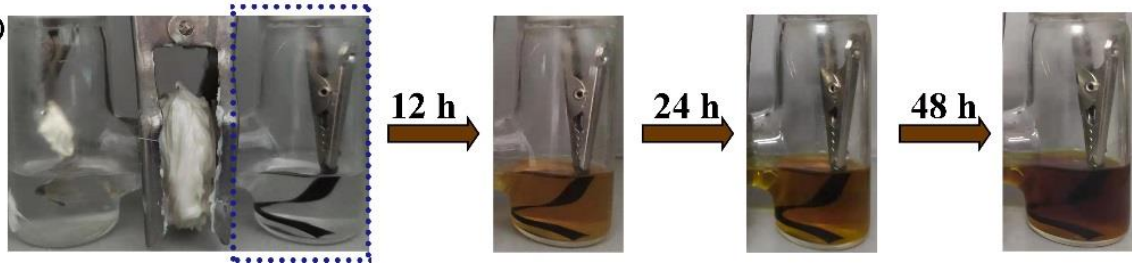

Figure S20. Visualized cell prototype with (a) $\alpha-C D @ C M K-3 @ S$, and (b) $\gamma$-CD@CMK-3@S as cathodes. In either case, lithium polysulfides gradually dissolved over time and completely filled the blank electrolyte after $12 \mathrm{~h}$.

Table S4. The element composition of the deposition on the lithium anodes after certain cycles from EDS analysis.

\begin{tabular}{cccccc}
\hline Names & $\mathbf{C}$ & $\mathbf{N}$ & $\mathbf{O}$ & $\mathbf{F}$ & $\mathbf{S}$ \\
\hline CMK-3@S & 15.06 & 2.73 & 46.31 & 16.30 & 19.62 \\
$\alpha-\mathrm{CD} @ \mathrm{CMK}-3 @ \mathrm{~S}$ & 11.64 & 3.64 & 55.61 & 16.79 & 12.32 \\
$\beta$-CD@CMK-3@S & 9.54 & 4.02 & 67.57 & 15.52 & 3.35 \\
$\gamma$-CD@CMK-3@S & 11.33 & 2.79 & 60.95 & 13.76 & 11.17 \\
\hline
\end{tabular}

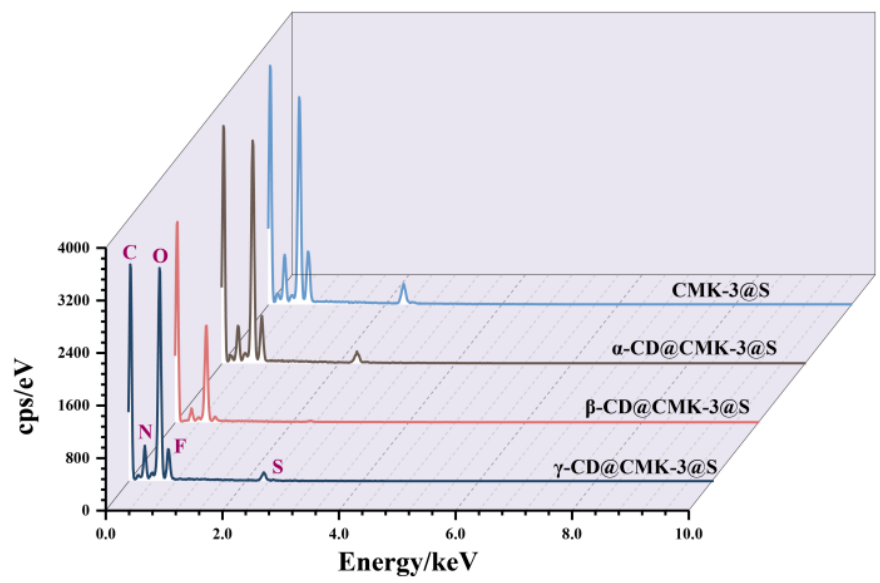

Figure S21. The EDS analysis of the deposition on the lithium anodes after certain cycles. In the case of $\beta-\mathrm{CD} @ \mathrm{CMK}-3 @ S$ electrode, the integral area of peak assigning to element sulfur is minimum, showing that $\beta-\mathrm{CD}$ molecules possess the effective inhibition effect on the polysulfide shuttle. 


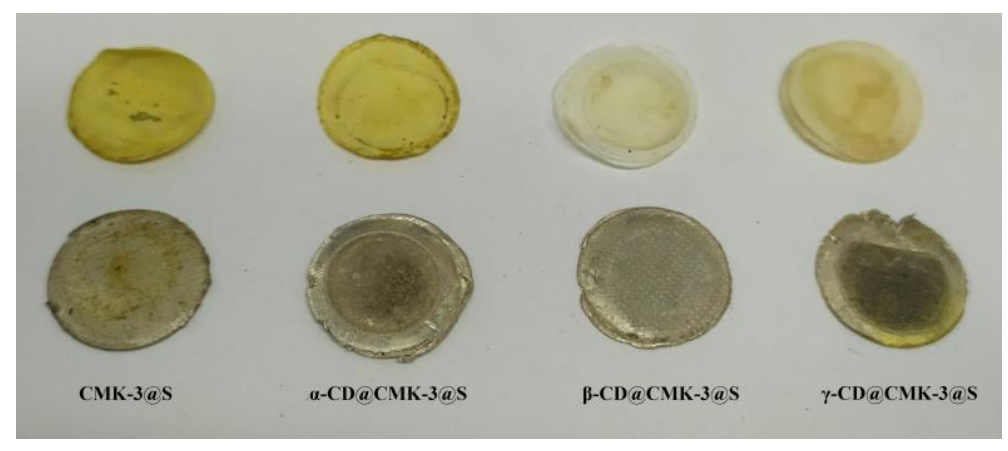

Figure S22. Photos of lithium anodes after certain cycles. The shuttle of polysulfides yellowed the metallic lithium electrode. In the case of the $\beta$-CD-modified cathode, $\mathrm{Li}$ slice and separator were almost colorless, showing an optimal capability in constraining polysulfide shuttle.

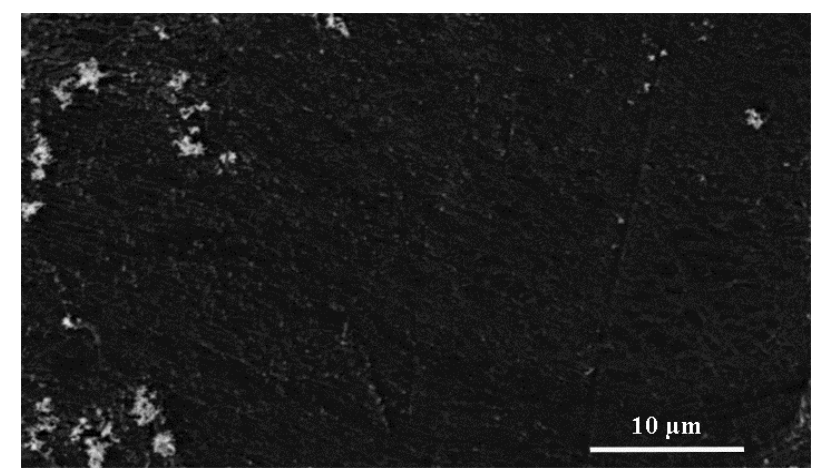

Figure S23. SEM images of lithium anodes with $\beta$-CD-modified cathodes after certain cycles. The visible powder was the deposition of unwashed LiTSFI.

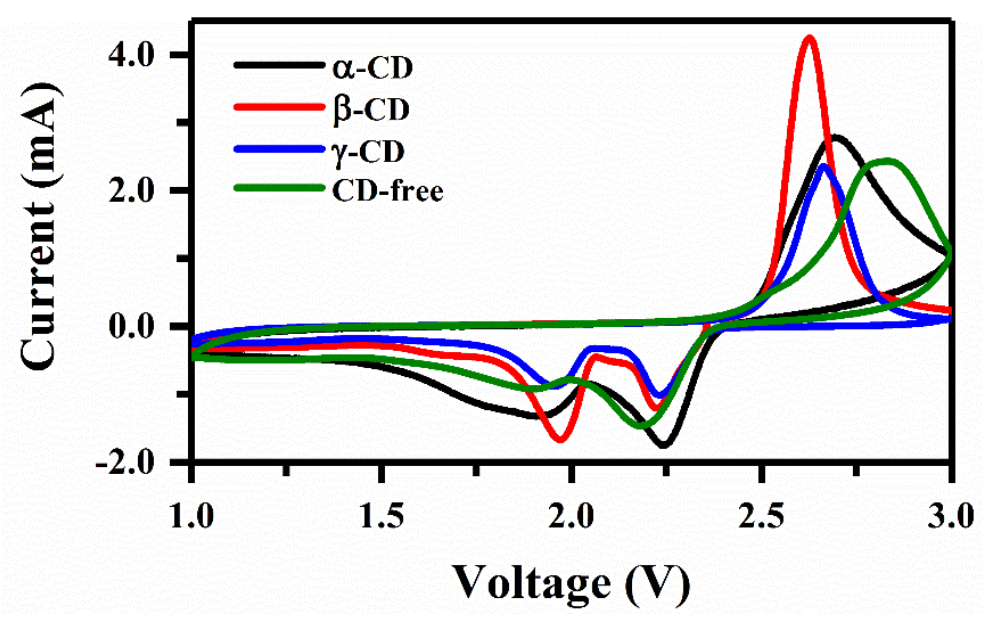

Figure S24. The comparison of the $\mathrm{CV}$ profile of four cells tailored with $\alpha-\mathrm{CD} @ \mathrm{CMK}-3 @ \mathrm{~S}, \quad \beta-\mathrm{CD} @ \mathrm{CMK}-3 @ \mathrm{~S}, \quad \gamma-\mathrm{CD} @ \mathrm{CMK}-3 @ \mathrm{~S}, \quad$ and $\mathrm{CMK}-3 @ \mathrm{~S}$, respectively. 


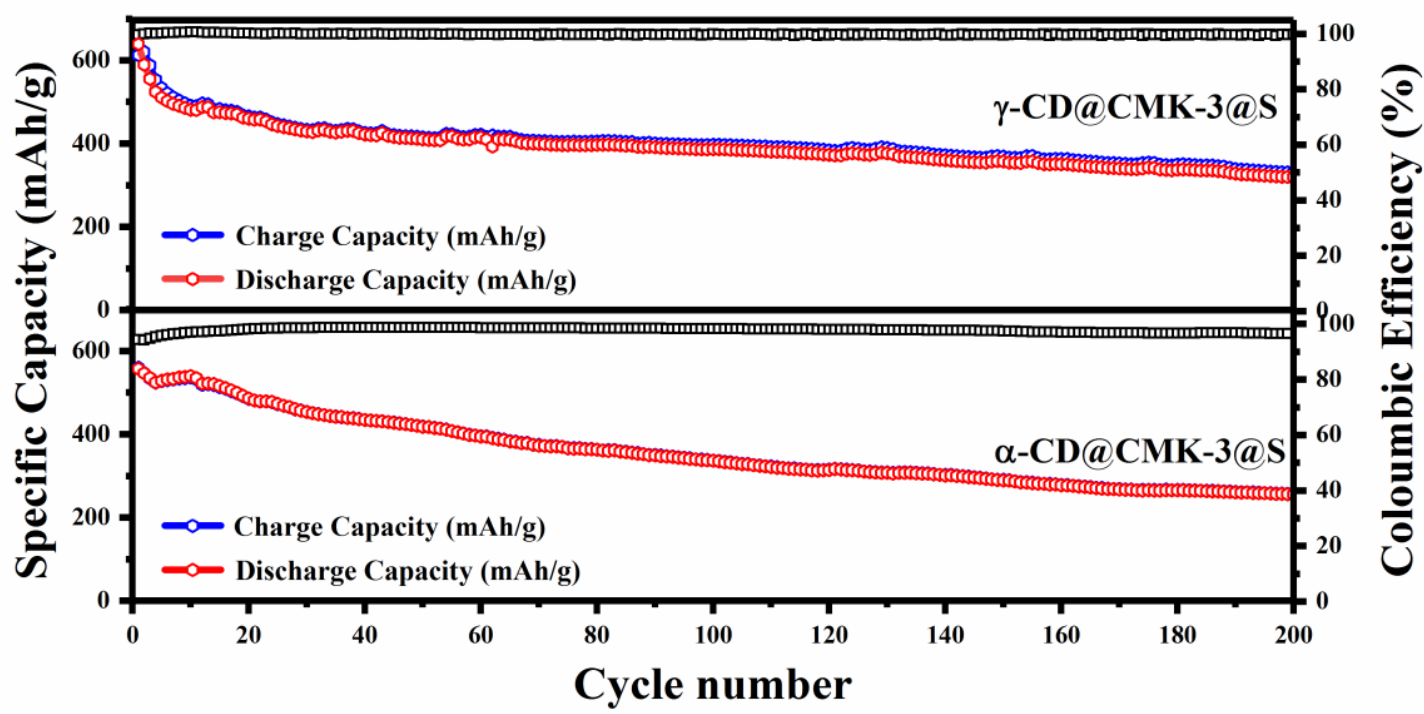

Figure S25. Cycling performances of the cells modified with $\alpha-\mathrm{CD}$ and $\gamma$-CD at $0.5 \mathrm{C}$ rate over 200 cycles.

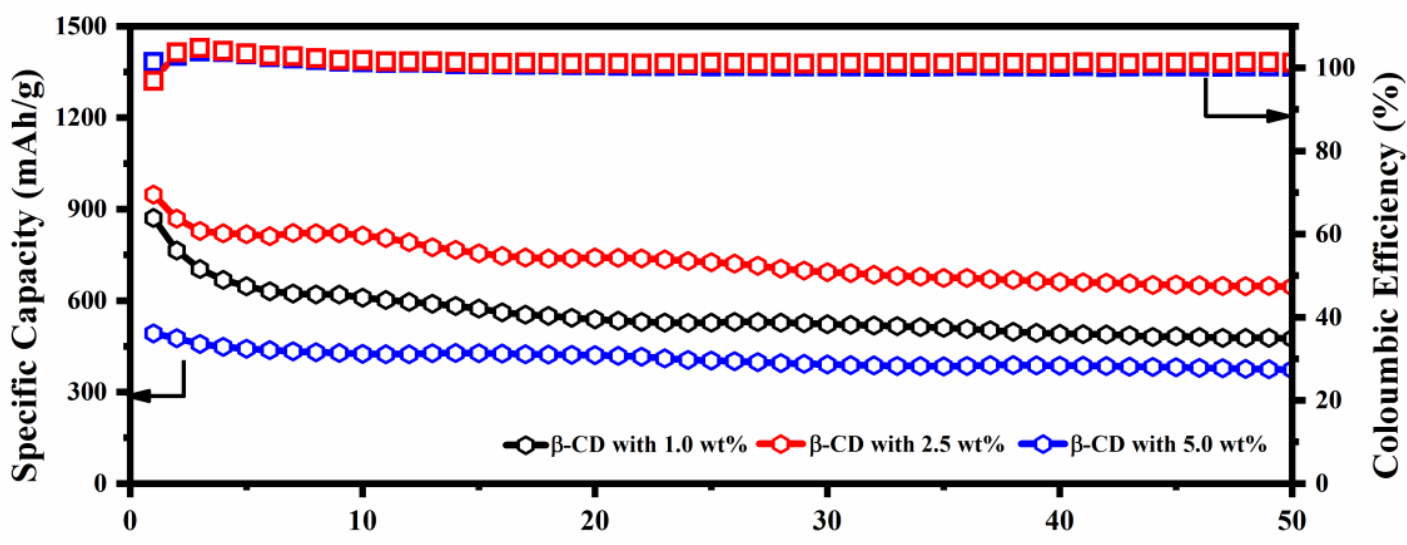

Cycle number

Figure S26. Discharge capacity profiles and coulombic efficiency at a rate of $0.5 \mathrm{C}$ by studying CMK-3@S cathodes with different dosage of $\beta$-CD molecules. 


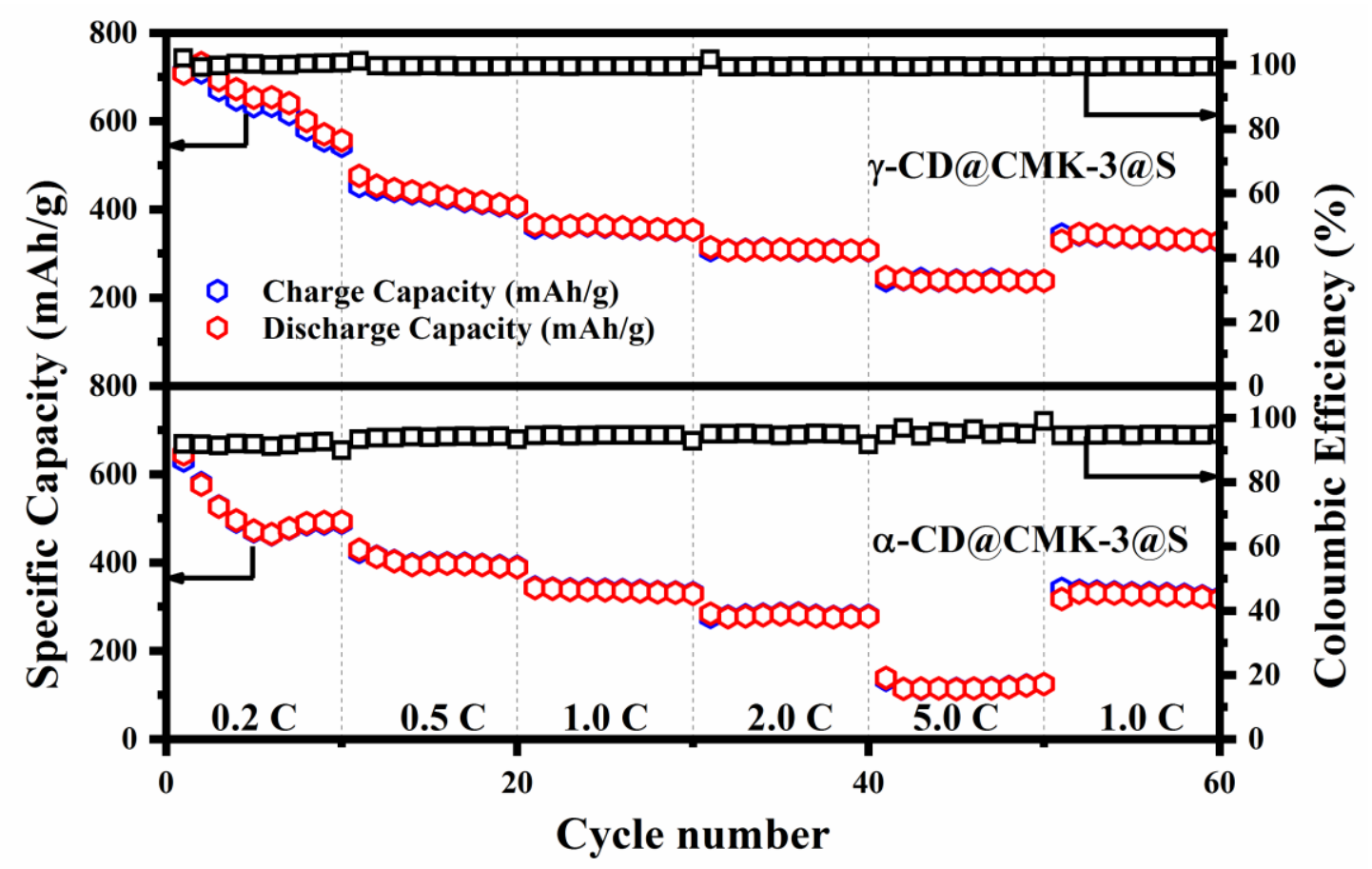

Figure S27. Rate performance of lithium-sulfur batteries with $\alpha-\mathrm{CD}$ and $\gamma-\mathrm{CD}$ as cathodes at various $\mathrm{C}$-rates from $0.2 \mathrm{C}$ to $5.0 \mathrm{C}$ and back to $1.0 \mathrm{C}$. 